\title{
Anticancer Drug Development, Breakthroughs are Waiting
}

\author{
Lu DY1*, Lu TR ${ }^{1}$, Yarla $\mathrm{NR}^{2}$, Xu B ${ }^{3}$, Chen $\mathrm{EH}^{3}$ and Ding J ${ }^{3}$ \\ ${ }^{1}$ School of Life Sciences, Shanghai University, Shanghai, China \\ ${ }^{2}$ Divisions of Biochemistry \& Chemistry, City University of New York School of \\ Medicine, USA \\ ${ }^{3}$ Shanghai Institute of Materia Medica, Chinese Academy of Sciences, Shanghai, China
}

\section{Mini Review \\ Volume 2 Issue 1}

Received Date: November 15, 2017

Published Date: December 01, 2017

*Corresponding author: Da-Yong Lu, School of Life Sciences, Shanghai University, Shanghai, China, E-mail: ludayong@shu.edu.cn

\section{Abstract}

New anticancer drug discovery, development and manufacture are entering into bottleneck stage at this moment. Many obstacles of biomedical, pharmaceutical, technology and economics lead to staggering pace of anticancer drug developments more recently. A declining successful rate of phase II and phase III anticancer drug evaluations is losing a great sum of money as well as human resource potentiality throughout the world. This editorial addresses some key factors affecting anticancer drug developments and providing possible avenues for drug development breakthroughs.

Keywords: Anticancer drug development; Neoplasm metastasis; Cost-effective; Medicinal chemistry; Animal models; Drug toxicity; Cancer stem cells; Individualized cancer therapy

Abbreviations: MDR: Multi-Drug-Resistances; BRICS: Brazil, Russia, India, China and South Africa; ATCC: America Tissue Culture and Collection

\section{Historic Backgrounds}

Cancer is a malignant disease that costs 7-10 million human mortality annually worldwide. The greatly human mortality by cancer is caused by shortage of effective anticancer drugs, especially antimetastatic drugs [1-4]. Nevertheless drug discovery, development and manufacture have been entering into bottleneck stages since this Millennium--drug revenue declining year-byyear [5-10]. Each anticancer drug licensing overall needs 1-2 billion USD in US and other developed countries. Thus anticancer drug discoveries and developments are highly risky processes and expose negative impacts for healthy progresses of drug development and manufacturing worldwide [10].

\section{Drug Development Dillema}

1. Myriad chemicals, biological materials and techniques are waiting to be evaluated. It makes decision-making difficultly [6].

2. Since many biological or pathological properties of cancers, such as neoplasm metastasis and cancer stem cells have not been well understood [11-14].

3. Current policy of anticancer drug licensing is that new compounds must be more effective than licensed anticancer drugs. This is a paradox issue because cancer is a different disease that needs to be targeted or treated by different anticancer drugs [15].

4. New genomic data explosion, it needs time to consume.

Owing to these modality difficulties and high economic investments, it is almost a franchise to small numbers of developed countries (mostly US, UK, German and Swiss). As an opponent of these small numbers of developed countries, BRICS (Brazil, Russia, India, China and South 


\section{Advances in Pharmacology and Clinical Trials}

Africa) countries and intermediate industry countries, such as Australia, Italia Spain, Austria and so on ought to pay expanding attentions on drug developments in their broader markets [16].

\section{Cancer Modality}

\section{Great diversity of cancer models}

Anticancer drugs are divided into wide-spectra and narrow-spectra that often act onto different types of animal or human tumor modality. Present in vitro or in vivo drug screening animal or human tumor models are enormously diversified. For example, approximately 1,200 human tumor cell lines are stored for anticancer drug screening, verifications and mechanism explorations in America Tissue Culture and Collection (ATCC), USA. As a result, proper budget control systems must be established.

\section{Pathologic-pharmacologic relations}

Different tumor inoculation routes affect new compound responses/efficacy outcomes. In vivo tumor models of subcutaneous locations (sc), intraperatoneal (ip), intravenous (iv), hollow-fiber, ectopic tumor origins or xenografts from human tissues may obtain different types of anticancer agents. Similarly, environmental factors or surroundings can aid tumor tissues originally survival and progresses in animal or human bodies $[17,18]$. With these experimental advancements, more effective anticancer drugs are waiting.

\section{Tumor metastasis models}

Antimetastatic agents or drugs developments need to be promoted because $90 \%$ cancer patient mortality is from neoplasm metastasis [11-14]. Even though widely notification, currently experimental tumor metastatic models are insufficient for harvesting effective antimetastatic drugs and therapeutics. Shortage of widespectra and highly active antimetastatic drugs is a serious problem for clinical utilities and therapeutic significance for late-staged and aged cancer patients [14].

\section{New generations of drug screening models}

Though new generations of in vitro or in vivo tumor models are invented quickly, the overall outlook of anticancer drug development systems changed slightly. It means we did not hit the bull's eye of anticancer drug developments in the past. Overall, it is not the time to debate or nullify previously discovered processes. It is the time to integrate and jigsaw these pieces and puzzle altogether. Dynamic mechanisms of oncogenic- and metastatic- genes or predispositions are of high scientific and medical value. Nonetheless, this stage of drug screening systems has less integral models of tumor progresses and metastasis for therapeutic significance. It needs new ideas and state-of-the-art techniques.

\section{Avant-garde experimental equipments and lab facilities}

Apart from animal or human tumor models, avantgarde experimental equipments and lab facilities can also improve the drug evaluation qualities. Nonetheless advancements of new anticancer drug discovery by this avenue have been very limited while the cost of anticancer drug developments is soaring since this Millennium. Strangely enough, these advancements of tumor models and automation help us to reclaim a number of withdrawal anticancer drugs [19-20]. The mechanisms behind the scenery are interesting areas of anticancer drug developments.

\section{Anticancer drug developments, a matter of money or a matter of ideas}

Anticancer drug developments, a matter of money or a matter of ideas is an important question to be resolved [8]. From above-mentioned topics, greater parts of topics are addressing on an area of techniques (money issue). Similarly, scientific investigations need high quality of researchers (personnel issue). Money is always easier to collect than marvelous researchers. But it is indispensable in initial stages. These kinds of money issue cannot sustain. High quality of drug researchers will decide how long we can go for.

\section{Different drug combinations}

Cancer is a malignant disease that is often difficult to be managed. To overcome these obstacles, anticancer drug combination is a useful way to improve therapeutic outcomes in clinical cancer trials. These kinds of efforts need long-term hard work [21-22].

\section{Future Trends}

Currently, cancer chemotherapy faces two most difficult problems, neoplasm metastasis and multi-drugresistances (MDR). Among these two thorny problems, treatment of neoplasm metastasis is especially difficult at this moment. Also, metastasized tumors often concomitantly manifest the characters of MDR. As a result, pinpointing tumor origins/categories for new tested compounds is suitable for making experimental, preclinical and clinical drug evaluation smarter. It can be the utility of clinical tumor samples into drug 


\section{Advances in Pharmacology and Clinical Trials}

development stages $[23,24]$ or study some new tumor functionality, such as stem cancer cells [25-27]. Any small breakthroughs will be very useful for obtaining smarter cancer therapeutic options.

\section{Conclusion}

Owing to the slow progresses of anticancer drug development chain, rethink and retrospect past experience is quite necessary. In future, higher efficient experimental tumor growth or metastasis models and good governmental regulatory measures must be implemented by modernizing lab facilities and finding relevance good clinical paradigms worldwide. We welcome global participations for new eras of anticancer drug discovery and developments.

\section{References}

1. Mina LA, Sledge GW (2011) Rethinking the metastatic cascade as a therapeutic target. Nat Rev Clin Oncol 8(6): 325-332.

2. Lu DY, Lu TR (2010) Antimetastatic activities and mechanisms of bisdioxopiperazine compounds. Anticancer Agents Med Chem 10(7): 564-570.

3. Lu DY, Lu TR, Cao S (2012) Cancer metastases and clinical therapies. Cell \& Developmental Biology 1(4): e110.

4. Lu DY, Lu TR, Wu HY, Cao S (2013) Cancer Metastasis treatments. Current Drug Therapy 8(1): 24-29.

5. Merris J (2005) Productivity counts-but the definition is key. Science 309(5735): 726-727.

6. Ruggeri BA, Camp F, Miknyoczki S (2014) Animal models of disease: Preclinical animal models of cancer and their applications and utility in drug discovery. Biochem Pharmacol 87(1): 150-161.

7. Herter-Sprie GS, Kung AL, Wong KK (2013) New cast for a new era: preclinical cancer drug development revisited. J Clin Invest 123(9): 3639-3645.

8. Lu DY, Chen EH, Lu TR (2015) Anticancer drug development, a matter of money or a matter of idea? Metabolomics 5(2): e134.

9. Lu DY, Ding J, Chen RT, Xu B, Lu TR (2016) Antimetastatic activities and mechanisms of action among Bisdioxopiperazine compounds. Pharmaceutical Formulation and Medicinal Chemistry: Mechanisms, Developments and
Treatments. Moore B (Ed.), chapter 2, Nova Science Publishing, US, pp: 73-106,

10. Lu DY, Lu TR, Zhu H, Ding J, Xu B, et al. (2017) Anticancer drug development, getting out from bottleneck. Int J Mol Biol 2(1): 00010.

11. Gupta GP, Massague J (2006) Cancer metastasis: building a framework. Cell 127(4): 679-695.

12. Talmadge JE, Fidler IJ (2010) The biology of cancer metastasis: historical perspective. Cancer Res 70(14): 5649-5669.

13. Valastyan S, Weinberg RA (2011) Tumor metastasis: molecular insights and evolving paradigms. Cell 147(2): 275-292.

14. Lu DY, Lu TR, Xu B, Qi RX, Sastry NY, et al. (2016) Cancer metastasis, a clinical dilemma for therapeutics. Current Drug Therapy 11(2): 163-169.

15. Schein PS, Scheffler B (2006) Barriers to efficient development of cancer therapeutics. Clin Cancer Res 12(11): 3243-3248.

16. Lu DY, Lu TR, Chen EH, Xu B, Yarla NS, et al. (2017) Anticancer drug development, system updating and global participation. Current Drug Therapy 12(1): 37 45 .

17. Dvorak HF (2015) Tumor stroma, tumor blood vessels, and anti-angiogenesis therapy. Cancer J 21(4): 237-243.

18. Dvorak HF, Weanor VM, Tisty TD, Bergers G (2011) Tumor micro-environment and progression. J Surg Oncol 103(6): 468-474.

19. Ali I, Wani WA, Saleem K, Haque A (2012) Thalidomide: a banned drug resurged into future anticancer drug. Current Drug Ther 7(1): 13-23.

20. Gupta SC, Sung B, Prasad S, Aggarwal BB (2013) Cancer drug discovery by repurposing: teaching new tricks to old dogs. Trends Pharmacol Sci 34(9): 507517.

21. Lu DY, Chen EH, Wu HY, Lu TR, Xu B, et al. (2016) Anticancer drug combination, how far we can go through? Anticancer Agents Med Chem 17(1): 21-28.

22. Lu DY, Lu TR, Yarla NS, Wu HY, Xu B, et al. (2017) Drug combination in clinical cancer treatments. Rev Recent Clin Trials 12 PMID: 28782482. 


\section{Advances in Pharmacology and Clinical Trials}

23. Span PN (2015) From eels to the importance of cancer bio banks. Future Sci OA 1(4): FS065.

24. Pirnia F, Frese S, Gloor B, Hotz MA, Lueth A, et al. (2012) Ex vivo a assessment of chemotherapyinduced apoptosis and associated molecular changes in patient tumor samples. Anticancer Res 26(3A): 1765-1772.

25. Yakisich JS (2012) Challenges and limitations of targeting cancer stem cells and/or the tumour microenvironment. Drug and Therapy Study 2(1): e10.

26. Park TS, Donnenberg VS, Donnenberg AD, Zambidis ET, Zimmerlin L (2014) Dynamic interactions between cancer stem cells and their stromal partners. Curr Pathology Rep 2(1): 41-52.

27. Magee JA, Piskounova E, Morrison SJ (2012) Cancer stem cells: impact, heterogeneity, and uncertainty. Cancer Cell 21(3): 283-296. 